\title{
The Innovation Study of e-Business Mode based on big Database Environment
}

\author{
Shifang Liu ${ }^{1, a}$ \\ ${ }^{1}$ Chongqing Electric Power College, Chongqing, China \\ a527545971@qq.com
}

Keywords: Big database, Database Environment, Electronic commerce, Innovation study

\begin{abstract}
Big database is in a variety of ways and path affects the enterprise's business ecosystem, it has become a basic business model innovation. In this paper, on the basis of the interpretation of the large data analysis of large data of business model innovation, reveals the database in key business enterprise value proposition, innovation and process innovation, revenue model, the relationship between the external network and value the application of network reconfiguration; Along the large data in large data industry chain, the lateral extension of product value chain, this paper provide a complete solution oriented business model innovation, for the enterprise in the era of big data for business model innovation breakthrough point provides a systematic analysis framework.
\end{abstract}

\section{Introduction}

Big database is usually refers to a kind of unstructured or semi-structured data. Its characteristics can be summarized as four points: the first is the amount of data. Now the big data level of the amount of data has jumped from TB level to the level of $\mathrm{PB}$, and growth trend continues to accelerate. With large size and growth of the unstructured data according to the total amount of $80 \%$ to $90 \%$, is 10 to 50 times of traditional data warehouse. The second is the data type is various. Web logs, video, images, and even geographic location, purchase records, all belong to the category of large data. The third is the high density value [1]. Continuous uninterrupted monitoring process will be filled with a large number of unrelated information, useful data rarely. And big data can through analyzing the future trends and patterns can predict high use value for people in the business consulting and report [1]. The fourth is processing speed is fast. Big data processing need real-time analysis, data input, processing can be done in a sequence of steps in the short term.

Market research firm Gartner, in 2012, expects full-year directly or indirectly for big data driven by global IT spending of $\$ 96$ billion, the data will reach $\$ 120$ billion in 2013, the 2015 global will add 4.4 million jobs IT to support large data, 2016 to $\$ 232$ billion. Turing award winner Jim gray and IDC also predicted that global data volume can be doubled every 18 months [1]. McKinsey said in a report on the big data on 2011, big data has penetrated into every industry and business functional areas, gradually become important production factor, and people for the use of the huge amounts of data will herald a new wave of productivity and the growth of consumer surplus. Taobao new daily transaction data of 10 TB [1]; EBay analysis platform, process the data quantity is as high as $100 \mathrm{pb}$, throughout the day than the nasdaq exchange of data processing; Amazon deal with 72.9 per second order. These examples show that the global especially e-commerce site, ushered in the era of big data. Data become more and more useful resources, e-commerce enterprises in the development and utilization of big data market there are great prospects for development.

\section{The Innovation of Electronic Commerce based on big Database Environment}

The advent of the era of big database for the development of e-commerce has brought the change of idea and a new data management mode, make the database of actual application and enterprise operation can be more closely combined, thus pushing service mode innovation. Large amount of consumption database provides the electricity enterprises grasp the user consumption pattern, the basis of the electric business enterprise through the use of big database can be personalized, accurate and intelligent advertising push service, to create a more interesting and effective service model 
(Shown in Fig.1) [2]; At the same time, the electricity business enterprise can also pass the assurance of pair of big database, looking for more and better increase user stickiness, develop new products and services, to reduce the operation cost method.

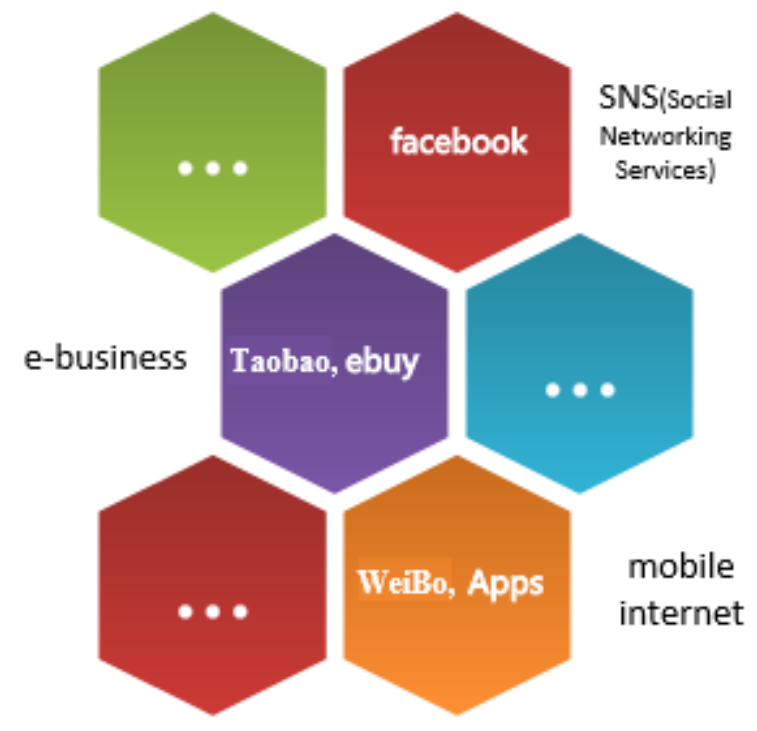

Fig.1 Electronic business model in the case of large database

Digital electronic commerce operation. Big database environment, electricity companies to use database to more operational, almost all links within the enterprise can use to render the data form. Both mid of procurement, marketing and financial accounting can be used in the late manage data view, so as to optimize the efficiency of various business node [2]. Amazon through the analysis and prediction of customer demand and consumption, adopt different strategies to satisfy the customer the different demand for goods sell like hot cakes, long tail goods, reducing management costs and logistics costs.

E-commerce database capitalization. Big database electronic commerce enterprise under the environment of competition, the competition will be has the database scale and active. The economic benefits of big database and function increasingly taken seriously by enterprise, to produce a lot of business about the data. Supplier start to provide data analysis service, for example, by users of unstructured data provide standard report and data services [3]; Data visualization services, to display the database in the form of visualization of the scale and characteristics. Some scholars think that the role of big database in the future will be like infrastructure, database of cross reuse will be widely used. For example, Google very well with large database, increase the economic benefit. Although Google all software applications can be free to use [2], but by Google users in the use of the product when the behavior of the exposure, hobbies and so on big database integration, to be able to more deeply understand the characteristics of the user, to help advertisers advertise more precisely.

Connect big database platform e-business model [3]. High connectivity and high availability of large database abundance sex brought about big database business activity rate marketization of a sharp rise in these activities not only show the deal also includes between market mechanism and hierarchical mechanism of all kinds of cooperation and big database business and other business within the enterprise trading refers to the combination of the sharp rise in the frequency of intercourse activities about big database to make the transaction cost saving enterprise design trade structure and trade mechanism at the center of attention problem is to determine the key issues of the whole economic efficiency on the other hand the development of the large database and reduce transaction costs for various barrier-free communication open information and standards such as asset specificity to reduce a few joint platform business model is not only due to lower transaction costs and transaction costs resulting from the need to reduce platform is the result of the enterprise in the business ecosystem plays a more and more important role in the logic of the business model to create value is that by connecting with a lower polymerization platform participants the transaction cost and makes the network effect of the parties. 
Create big database as the center of the electronic commerce mode. Continuously strengthen the data of the era of large data integration ability, makes the electric business enterprise much easier and more convenient information and resource sharing with the supply chain upstream and downstream (shown as Fig.2), the transition between the enterprise boundary is fuzzy, so that the end user the focus of attention focused on how to care about and solve their own problems. So in the industry value chain, the closer it gets to the end user stores its living space [4].

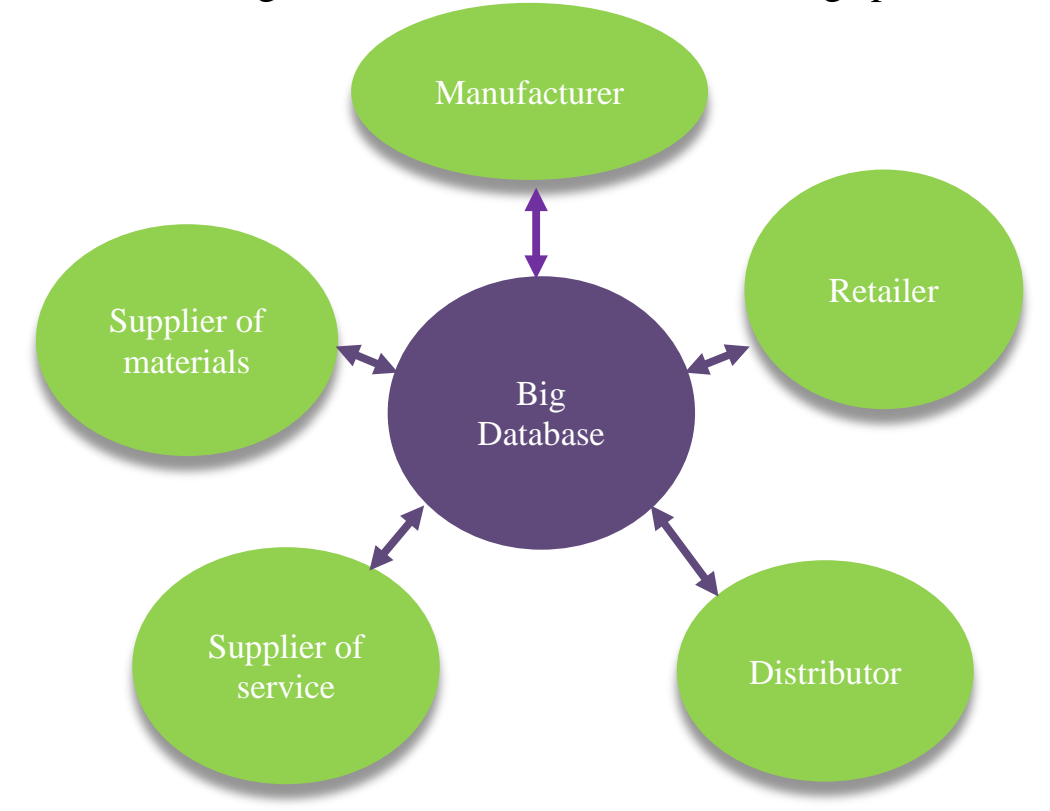

Fig.2 Big database as the center of the electronic commerce mode

E-commerce by big database guide realize the personalized service. Under the background of big database will provide personalized service and third party service providers, the combination of guide can find personalized e-commerce service mode [4]. Buy personalized service needs the support of a large amount of database, including the user's browsing history, purchase, consumer preferences, and so on.

Through the database mining on the large data, are derived from the main two ways, namely personalized ads and personalized recommendation. Personalized advertising refers to recommend the user through the analysis of users' web browsing behavior more interested in the ads. Personalized recommendation is refers to the e-commerce site, the background of vast amounts of user behavior data for quick analysis, recommend user need most at this stage, the most suitable products. This approach will undoubtedly promote business sales grow very fast, but how to accurately measure the user's interest is still a problem [5]. At present most e-commerce sites is based on similarity recommended items. Medical WebMD, such as the United States is on the basis of pregnant women user fill in the conception of information, regularly send email for her mother, remind them in different stages of considerations, such as prenatal nutrition physiological changes and the thought preparation, need baby, postpartum recovery, a breeding and health, and so on.

E-commerce services digital products. According to the combination of basic services and independent server can be unearthed data service e-commerce service model. Big database has made it more important data environment, all electric business enterprise wants to obtain and fully understand the business of obtained information about customer data, but the fact is these electricity often don't have enough budget or advanced technology allows for the large data for further reading [6]. So for those who have platform and capital advantage of e-commerce enterprises, the advantage of them to use their own platform, will gain the huge amounts of data through the transition of packaging need marketing to small and medium-sized enterprises, thus opens up a new mode of e-commerce services. For example, the world's largest supplier of business-oriented social network data Grip through multiple API data aggregation into unified format, for Facebook, You Tube, sine web social networking sites such as data mining, to provide the data aggregation service [6]. 
Through professional formed for huge amounts of data mining into the merchant's multiple data products and development of products for the database provided by the third party. Including other e-commerce sites to provide data products and software, to provide all kinds of web sites and community social electricity business solutions, provide the seller with all kinds of optimization tools, and provide consumers with all kinds of optimization tools and so on.

\section{Summary}

For a long time, business model innovation study has two aspects: one is the only stay in the exploration of the abstract theory and reasoning, lack of practical maneuverability, 2 it is limited to the specific analysis of individual cases, the lack of systematic theory, so that these studies in guiding the role of enterprise business model innovation practice is extremely limited. Reflected in the reality, the enterprise must carry on the business model innovation is not in. Although case personalized business model innovation is very strong, but the business model innovation is not a whim.

In today's business model innovation vigorously, the complicated phenomenon of business model innovation will be hidden behind some regularity, to trace the business model innovation Find the trigger, know where it comes from to explore where it will, big data is an important clue. In big database for clues, to rethink their business models, design and innovation, is the important source of enterprise to obtain the overall structural difference advantage. The arrival of the big database is a process from quantitative change to qualitative change, it can realize the virtual world and physical world of match, the matching of historical database and real-time database, behavior way and the situation of the match, making it impossible for the many possible, big database not only brings a new kind of strategic resources and core competence, and it can realize enterprise and even the society as a whole way of control and utilization of resources, configuration, virtualization and open, improve resource use efficiency and economic efficiency, consciousness of "big database", "big database thinking" should become the basic knowledge of the business model innovation leader today.

\section{References}

[1] D. Sh. Zhang, The big data research and development, Computer technology, 2013.pp.12-16.

[2] J.F. Wu, Big data error analysis and using big data in retail, Win business network in China, 2013, pp33-37.

[3] J. Han and X.P. Du, big data service several key technology research, Beijing University of posts and telecommunications, 2013, pp.58-62.

[4] L.D Jia, Big data era business model change, Journal of electronic, 2014, pp. $45-47$.

[5] J.L. Li and W.H. Chen, Slightly under the background of information age the traditional retail enterprise business model reform research, Computer proceedings, 2015, pp.24-27.

[6] G.J. Li and X.Q. Chang, The future of economic and social development in major strategic, Proceedings of China, 2013.pp.21-25. 